\title{
True False Response Terminology
}

National Cancer Institute

\section{Source}

National Cancer Institute. True False Response Terminology. NCI Thesaurus. Code C105761.

Terminology codelist used for any True False responses. 